\title{
The International Conferences on Dietary Assessment Methods
}

The first International Conference on Dietary Assessment Methods (ICDAM) was sure to be a success from the outset, even though the original organisers may have had some trepidation when taking their first planning steps. The first steering committee chaired by Marilyn Buzzard brought together an international group of nutrition scientists who had been instrumental in developing dietary methods and applying them to studies on nutrition and health. Having been part of a dietary assessment laboratory at the University of Minnesota, Dr Buzzard knew that there was science and art involved in collecting and analysing dietary data. However, this information had not been the focus of a public scientific forum even though dietary methods are the foundation for studies on the relation between diet and health.

The rational for these conferences was clearly stated by Dr Buzzard in the proceedings of the first conference ${ }^{1}$. They were: (1) the need for improved dietary assessment methods to enhance our understanding of diet-health relationships; (2) the need for improved dietary assessment methods to facilitate the development and monitoring of nutrition-related health objectives; and (3) the importance of international participation in the conference. After months of planning, the first conference got off the ground and was hosted by the University of Minnesota, in St. Paul, MN, USA, on 20-23 September 1992. The conference plans developed and the first conference objectives were established, and they have been consistent throughout the first decade of meetings. This was also the conference where the onion became the official logo and symbol for the conference. The onion, shaped like the world, was chosen as a symbol that would join the need for improving dietary methods with improving the nutritional status of individuals around the world. The proceedings from the first ICDAM were published in the American Journal of Clinical Nutrition, as Supplement 1S to Volume 59 in January 1994.

The second conference was convened on 22-24 January 1994 and hosted by Harvard University in Boston, MA, USA. Walter Willett and Laura Sampson were the co-chairpersons for this conference. The proceedings from this conference were published in April 1997 in the
American Journal of Clinical Nutrition as Supplement $4 \mathrm{~S}$ to Volume 65.

The third conference was the first time it moved outside the USA. It was hosted by Wageningen Agricultural University in Arnhem, The Netherlands, on 6-9 May 1998. Wija van Staveren and Elio Riboli were co-chairpersons. Abstracts from presentations at this conference are available in a 1998 issue of the European Journal of Clinical Nutrition, Volume 52, Supplement 2.

The themes for the conferences have varied over the years, but each time the focus on improving dietary assessment methods in order to improve the nutritional status of people around the world has remained present. Table 1 provides the themes for all of the past conferences and for the forthcoming conference in Chiang-Rai, Thailand, to be hosted by Mahidol University.

Although the growth of these conferences has been phenomenal, the relatively small size for each ICDAM has facilitated the exchange of scientific information and the creation and strengthening of networks between colleagues. The scientific sessions have included workshops, oral and poster presentations, and breakfast round tables. The first conference had a total of 110 presentations. However, the next two conferences saw double the original number of presentations (246 presentations in 1995 and 247 presentations in 1998) and the fourth conference had a total of 316 presentations. Obviously, the scientific community and the sponsoring agencies recognised the value of having a conference dedicated to dietary assessment methodology.

The rational and conference objectives have remained true to the original planning concepts, but have also been tailored at each conference to answer the new questions developed by researchers in order to improve dietary assessment methods. The conference sessions for the first four conferences are presented in Table 2. The first ICDAM started off by identifying gaps and setting the research priorities. By the time the second conference occurred, a series of new research had already responded to the identified gaps, and the issues of underreporting and the use of different statistical methods for analysing dietary data were some of the new topics emerging at the

Table 1 Conference themes for the International Conferences on Dietary Assessment Methods

\begin{tabular}{lll}
\hline Conference theme & \multicolumn{1}{c}{ Date } & \multicolumn{1}{c}{ Location } \\
\hline Assessing Diets to Improve World Health & $20-23$ September 1992 & St. Paul, Minnesota, USA \\
Combining Theory and Practice & $22-24$ January 1995 & Boston, Massachusetts, USA \\
Advances in Dietary, Biochemical and Statistical Approaches & $6-9$ May 1998 & Arnhem, The Netherlands \\
Promoting the Appropriate Use of Dietary Assessment Tools for All & 17-20 September 2000 & Tucson, Arizona, USA \\
Expanding the Horizon, Dietary Assessment in a Multi-cultural World & 26-29 January 2003 & Chiang-Rai, Thailand \\
\hline
\end{tabular}




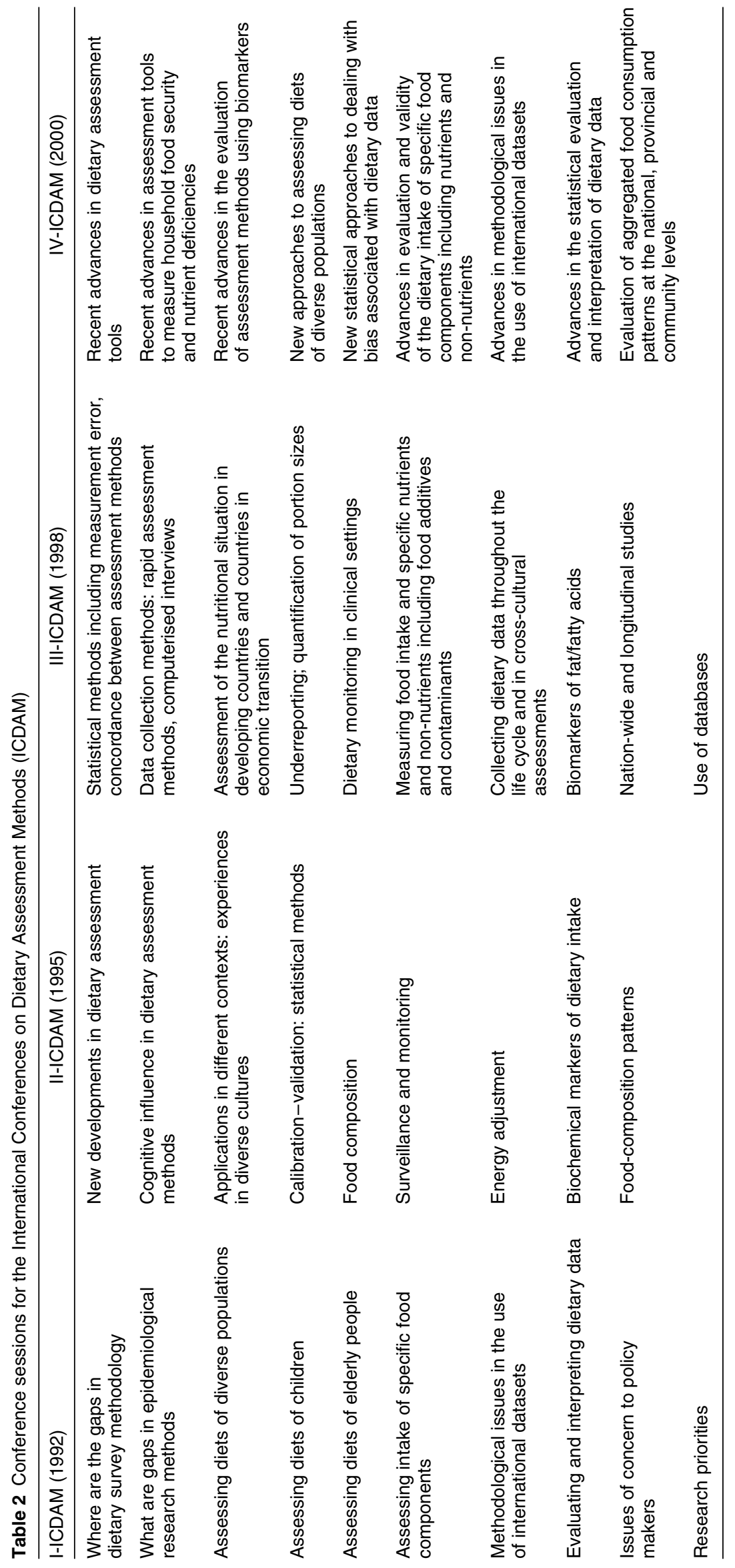


conference. Each conference has also considered how dietary assessment methods need to be developed to address differences in collecting data across age and cultural groups and for measuring the intake of specific food items. Improving methods to measure the intake of nutrients and non-nutritive substances in food for shortterm and long-term studies have been reported at each ICDAM. Improvements in computer technology have also made entering dietary data and the development of databases more accessible to nutrition researchers. Computers have also affected how dietary data are collected and analysed. An offshoot of the second ICDAM was the publication of the dietary assessment resource manual by Francis Thompson and Tim Byers in the Journal of Nutrition in November of $1994^{2}$.

A focus on analysing dietary data has also had a consistent presence at each ICDAM. Statistical methods for analysing dietary data have been a primary focus of each conference. The statistical factors have included such issues as describing the factors that affect the variance of energy intake within and between people, describing various types of measurement error, and the development and debate of various statistical methods for adjustments for measurement error.

Another growing field within dietary assessment methods has been the use of biochemical makers for validating dietary questionnaires and as proxy measures of dietary intake for specific nutrients. Reports on the use of biochemical markers have included the feasibility of doubly labelled water to validate measures of energy intake, and urinary markers for sodium intake and nitrogen intake. A session at the third ICDAM in Arnhem was dedicated to the use of biomarkers as an avenue for assessing the intake of fatty acids.

Dietary methods remain the cornerstone for epidemiological and intervention studies on nutrition and health.
Use of the proper dietary assessment method is important when making clinical decisions about the management of patients with nutritionally related diseases. These conferences have addressed the dietary methods that are used in studying (1) maternal and infant health, (2) chronic diseases, (3) non-nutritive substances, and (4) dietary supplements. Sessions dedicated to methods for determining the extent of food insecurity, hunger and micronutrient deficiencies in developed and developing countries have also been part of the conferences. Throughout the conferences there have been sessions on how to better collect dietary data, validate new methods, and improve statistical methods for the analysis of dietary data. From the collective effort of the researchers and participants at these conferences, the science of dietary assessment methods has advanced and will continue to improve our knowledge between nutrition and health. Finally, the published proceedings from these conferences are a valuable resource for students and researchers working in the field of nutrition and health and will remain so in the years to come.

\section{Douglas L Taren}

Conference Chairperson

University of Arizona College of Public Health 2231 East Speedway Boulevard

Tucson, AZ 85719, USA

\section{References}

1 Buzzard IM. Rational for an international conference series on dietary assessment methods. Am. J. Clin. Nutr. 1994; 59(Suppl.): 143S-5S.

2 Thompson FE, Byers T. Dietary assessment resource manual. J. Nutr. 1994; 124(Suppl. 11): 2245S-317S. 